\title{
ANALYSIS OF ALDICARB IN SURFACE WATER FROM THE PARANÁIBA RIVER
}

\author{
ALMEIDA, Monalisa Silva'; GOULART, Adilson Correia'; GOULART, Simone Machado; \\ SILVA, Tatiana Aparecida da ${ }^{1 ;}$ SANTOS, João Paulo Victorino ${ }^{1 *}$. \\ ${ }^{1}$ Instituto Federal de Goiás, Departamento de Química, Av. Furnas, ㄲo 55, Village Imperial, CEP: 75524-010, \\ Itumbiara - GO, Brasil (fone: +55 642103 5600; +55 642103 5626) \\ * Autor correspondente \\ e-mail: joao.santos1@ifg.edu.br
}

Received 25 May 2017; accepted 28 August 2017

\section{RESUMO}

O agrotóxico aldicarbe é o princípio ativo mais tóxico registrado em todo território nacional, destacando-se pela sua extrema toxicidade aguda. No ambiente, principalmente nos recursos hídricos, vários estudos têm demonstrado o potencial de contaminação do aldicarbe. ORio Paranaíba corta omunicípio de Itumbiara-GO, região considerada importante centro econômico do sul do estado. Ao longo da Bacia do Rio Paranaíba existe uma vasta gama de cultivos como, por exemplo, cana-deaçúcar, milho, soja, algodão. Este trabalho teve como objetivo analisar quantitativamente a ocorrência de contaminação por aldicarbe em águas superficiais do Rio Paranaíba, além disso realizar um estudo teórico do rio. Para tanto,empregou-se o método de extração líquido-líquido com partição a baixa temperatura(ELL-PBT) e análise por cromatografia líquida de alta eficiência com detector ultravioleta (HPLC-UV). Nas amostras de água superficiais do rio analisadas, não foram encontrados níveis de contaminação por aldicarbeou as concentrações ficaram abaixo do limite de detecção do método ELLPBT e HPLC-UV.

Palavras-chave:Agrotóxico; Análise de Aldicarbe; Rio Paranaíba.

\section{ABSTRACT}

The pesticide aldicarb is the most toxic active ingredient registered in all national territory, standing out for its extreme acute toxicity. In the environment, mainly in the water resources, several studies have demonstrated the potential of contamination of aldicarbe. The Paranaíba River cuts off the municipality of Itumbiara-GO, a region considered an important economic center in the south of the state. Along the Paranaíba River Basin there is a wide range of crops, such as sugarcane, corn, soy, cotton. This work aimed to quantitatively analyze the occurrence of aldicarb contamination in surface waters of the Paranaíba River, in addition to conducting a theoretical study of the river. For this purpose, the liquidliquid extraction with low temperature partitioning (LLE-LTP) and high-performance liquid chromatography (HPLC-UV) analysis were used. In the surface water samples of the river analyzed, no aldicarb contamination levels were found or the concentrations were below the detection limit of the LLE-LTP and HPLC-UV method.

Keywords: Pesticides; Aldicarb analysis; ParanaíbaRiver. 


\section{INTRODUÇÃO:}

A cada ano, a agricultura brasileira demonstra-se mais subordinada à utilização de agrotóxicos para aumentar produtividade agrícola, visto que o país é o maior exportador de grãos do mundo.O Brasil desde 2008 lidera o consumo de agrotóxicos em todo o mundo. Segundo último relatório do Instituto Brasileiro do Meio Ambiente e dos Recursos Naturais Renováveis, em 2014, foram consumidos nacionalmente mais de meio milhão de toneladas de princípios ativos (IBAMA, 2015).

Há vários anos a utilização dos agrotóxicos tem sido motivo de grande preocupação ambiental. São vários os estudos científicos que buscam relacionar e comprovar o crescimento da poluição ambiental com estes contaminantes (MEFFE; BUSTAMANTE, 2014). Isso se deve, principalmente, aos efeitos deletérios que estas substâncias, quando aplicadas, ocasionam ao ambiente, afetando seres não alvos de controle (LONDRES, 2011). Esta preocupação se estende mesmo após a degradação dos agrotóxicos no ambiente, isso porque, os produtos da degradação de alguns princípios podem ser mais tóxicos e nocivos aos ecossistemas (RICHARDSON; TERNES, 2014).

Quando aplicados, grande parte do princípio ativo atinge o solo e o ar e, com isso, moléculas destas substâncias podem ser carreadas em períodos de precipitação. Consequentemente, estas aportam nos recursos hídricos contaminando as águas superficiais. Uma vez contaminadas, essas águas superficiais estão propensas a propagarem esta contaminação, ocasionando efeitos irreversíveis aos ambientes aquáticos e até mesmo aos seres humanos (TOMLIN, 2000).

Os agrotóxicos podem ser classificados em função do seu grau de toxicologia, grupo químico e finalidade de uso. Quanto ao grau de toxicidade são divididos em: Extremamente tóxico; Altamente tóxicos; Medianamente tóxicos e pouco tóxicos. Quanto à estrutura química, classificam-se em inorgânicos e orgânicos, sendo o segundo grupo dividido em vários outros subgrupos. Os mais utilizados, quanto à classe de orgânicos, são os Organoclorados, Piretróides, Carbamatos e Organofosforados. As principais classes de agrotóxicos, quanto à finalidade de uso, são: Inseticidas (utilizados no controle de insetos); Fungicidas (para controle ou exterminação de fungos) e os Herbicidas (utilizados no combate às plantas indesejáveis)
YADAV; DEVI, 2017).

O princípio ativo aldicarbe é utilizado para produção do agrotóxico "Temik 150" ${ }^{\circledR}$. O produto é de uso exclusivo agrícola e autorizado para as culturas de café, cana-de-açúcar, algodão, citros e feijão. A substância tem como principal finalidade o combate a insetos, nematoides e ácaros. Destaca-se pela sua extrema toxicidade aguda, o que atribui ao ingrediente ativo o título de substância mais tóxica registrada em todo território nacional (ANVISA, 2016). Quimicamente é classificado como carbamato, é altamente solúvel e volátil, não é persistente no solo, é altamente tóxico para os seres humanos e possui baixo potencial de bioacumulação (UNIVERSITY OF HERTFORDSHIRE,2017).

No ambiente, estudos científicos têm demonstrado o potencial de contaminação ambiental do aldicarbe. Jackson; Mutch e Priddle (1990) encontraramaldicarbe em águas subterrâneas provindas da llha do Prícipe Eduardo, no Canadá, mesmo após dois anos de aplicação do produto. Castro e colaboradores (2005) analisaram a mobilidade do princípio ativo no solo. Com os resultados dos estudos, constataram que os resíduos do princípio ativo possuem alta mobilidade vertical nos solos estudados, o que atribui ao composto um grande potencial de contaminação de águas subterrâneas. Conhen et al., (1995) em seus estudos chegaram a mesma conclusão classificando o principio ativo em questão como tendo um elevado potencial de lixiviação.

Estudos demonstram que 0 aldicarbe possui grande toxicidade à fauna aquática, sobretudo para a maioria das espécies de peixes. Patrício e colaboradores (2002) testaram a toxicidade do princípio ativo em duas espécies de peixes BrachydanioRerio e Orthospinusfranciscensis. Constataram que a mortalidade das espécies acontecia em concentrações muito baixas para ambas as espécies $\left(1 \mathrm{mg} \cdot \mathrm{L}^{-1}\right)$. Em contrapartida, Rodrigues e colaboradores (2009) analisaram fígados de peixes da espécie Oreochromisniloticus, popularmente conhecidas como tilápia, e os resultados do estudo demonstraram a contaminação por aldicarbeem cerca de 13,3\% do total de amostras analisadas.

O município de Itumbiara destaca-se por ser um dos mais importantes centros econômicos do estado de Goiás. A região é cercada por uma vasta gama de cultivos como, por exemplo, canade-açúcar, milho, soja, algodão, entre outros. Os fatores que levaram a cidade a se sobressair na agricultura foram a boa localização, próxima a 
grandes centros urbanos 0 que facilita 0 escoamento da safra, e a privilegiada localização hidrográfica na Bacia do Rio Paraná, sendo cortada principalmente pelo Rio Paranaíba $(\mathrm{CBH}$, 2014 e IBGE, 2016). Segundo Rodrigues e colaboradores (2016) os carbamatos estão dentre os agrotóxicos utilizados na defesa das monoculturas no município de Itumbiara e região.

De acordo com a ANVISA (2016), a comercialização e uso de produtos formulados à base de aldicarbe estão autorizados somente para os Estados da Bahia, Minas Gerais e São Paulo, para agricultores certificados e propriedades cadastradas pela(s) empresa(s) fabricante(s). Entretanto, na cidade de Itumbiara é onde se encontra a divisa entre os estados de Goiás e Minas Gerais, sendo esses estados separados pelo rio Paranaíba.

A irrigação é o principal uso de água na bacia, vale ressaltar que a bacia apresenta uma grande variedade de culturas irrigadascom diferentes métodos que vão desde o gotejamento até pivô central $(\mathrm{CBH}, 2014)$.

O Rio Paranaíba, juntamente com o Rio Grande, é um dos formadores do Rio Paraná. Sua nascente está situada na Serra da Mata da Corda, no município de Rio Paranaíba/MG, possui altitude de cerca de $1.100 \mathrm{~m}$. Percorre aproximadamente $100 \mathrm{~km}$ até alcançar o perímetro urbano de Patos de Minas/MG e segue mais cerca de $150 \mathrm{~km}$ até tornar-se limítrofe entre os Estados de Goiás e Minas Gerais $(\mathrm{CBH}$, 2014). Nas margens do rio Paranaíba, tanto nas margens goianas quanto mineiras, é comum encontrar áreas utilizadas para agricultura. Mesmo em trechos urbanos, é possível observar plantações agrícolas, em especial o cultivo de cana-de-açúcar, cultura na qual se utilizam os carbamatos.Ademais, o rio Paranaíba possui vários afluentes que cortam toda a região agrícola do município aumentando as chances de ocorrer a contaminação de suas águas superficiais. Este trabalho teve como objetivo verificar, quantitativamente, a presença de contaminaçãoporaldicarbenas águas superficiais do rio Paranaíba, no município de Itumbiara/GO, bem como realizar um estudo teórico sobre o rio.

\section{PARTE EXPERIMENTAL:}

\subsection{Pontos de coleta}

Para definição dos pontos de coleta de amostras de água do rio Paranaíba, foi realizado um estudo teórico sobre o rio, denominado área de estudo.As coletas das amostras de águassuperficiais do rio Paranaíba foram realizadas dentro do perímetro urbano domunicípio de Itumbiara-GO. Foram delimitados 4 pontos de coletas,os mesmos foram determinados em função da verificação em loco da presença de cultivos de cana-de-açúcar próximos ao rio.

$\mathrm{Na}$ Figura 1 são apresentados os 4 pontos de coleta.

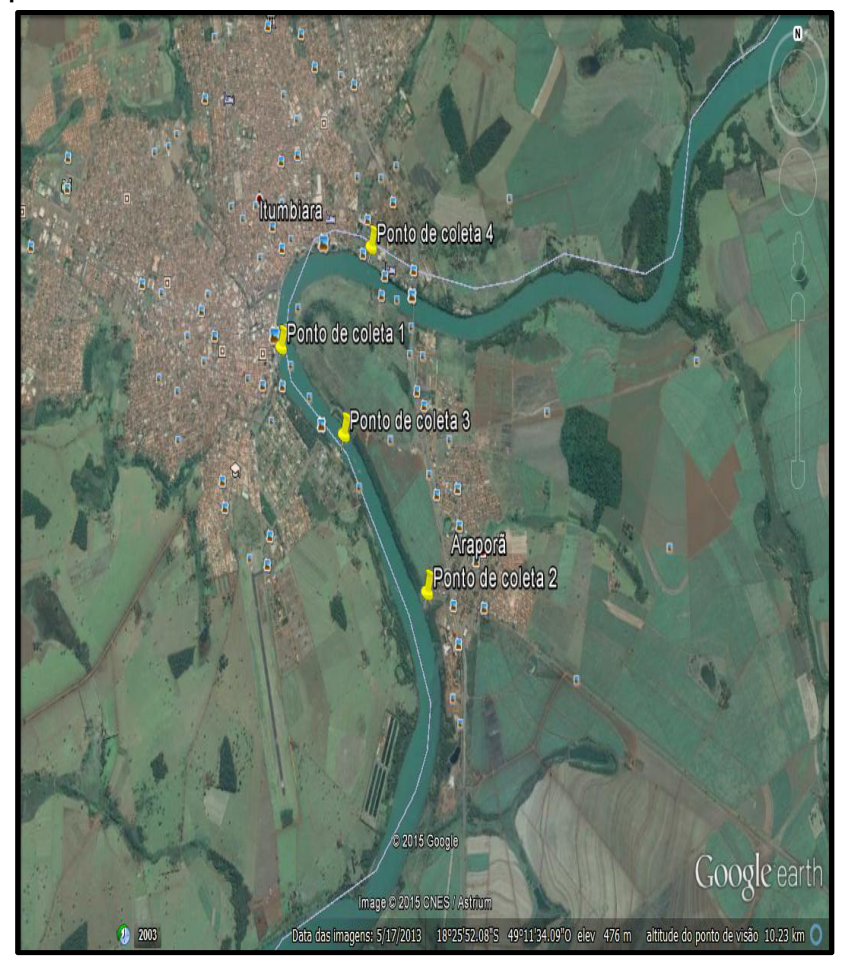

Figura 1: Pontos de coleta, Rio Paranaíba perímetro urbano de Itumbiara.

Fonte: EARTH (2015)

\section{Ponto 1 (1825'19.95's -}

49-12'46.60"O): Este ponto margeia parte do perímetro urbano da cidade. A montante deste ponto ( logo acima ao ponto de coleta) o rio recebe águas de pequenos córregos que antes de chegarem ao rio atravessam diversos tipos de terrenos os quais estão ocupados por diferentes tipos de cultura. Assim sendo, este ponto de coleta foi escolhido a fim de verificar se tais cursos d'agua estariam servindo como meio de transporte do aldicarbe para as águas do Rio Paranaíba.

\section{Ponto 2 (18\%26'24.59's -}

49911'34.56"O):A segunda amostra foi coletada proxima a plantações de cana-de-açúcar. Foi verificado que os canaviais foram plantados 
paralelamente às margens do rio, tendo como barreira entre as águas e a plantação, apenas a mata ciliar. Como dito anteriormente segundo a ANVISA o aldicarbe é recomendao para esta cultura. Desta maneira, este ponto foi selecionado com o intuito de verificar a possível relação entre a ocorrência de aldicarbe e o cultivo de cana-de-açúcar próximo ao Rio Paranaíba.

\section{Ponto $3 \quad$ (18²5'43.66"S}

49'12'15.45"O):O terceiro ponto amostral tem como principal característica a ocorrência de uma faixa de areia a qual serve como atrativo para o lazer náutico. O local é bastante visitado por banhistas e praticante de esportes aquáticos. É sabido que a dose letal de aldicarbe para os seres humanos é muito baixa.

\section{Ponto 4 (18\%24'52.00'S -} 49-12'02.94"O):O ponto 4 de coleta foi selecionado pelo mesmo motivo do ponto 1 . A montante do ponto de coleta o Rio Paranaíba recebe um importante afluente. À vista disso este ponto foi escolhido para verificar a interferência deste afluente nos níveis de aldicarbe no rio.

Em cada ponto delimitado, foram coletadas três amostras de águas superficiais.As amostras foram coletadas em frascos de vidro, sendo os recipientes previamente higienizados, enxaguados com água de torneira e destilada e rinsados por 2 vezes com a própria amostra na hora da coleta. Os frascos foram identificados e conservados em caixa de isopor com gelo, enviados ao laboratório e mantidos sob refrigeração a $4{ }^{\circ} \mathrm{C}$, até o momento da análise, que foi aproximadamente $24 \mathrm{~h}$ após a coleta.

\subsection{Curva analítica}

A quantificação do aldicarbe nas amostras de água foi realizada pelo método da padronização externa utilizando padrão analítico de aldicarbe. Uma solução padrão estoque na concentração de $1000,0 \mathrm{mg} \mathrm{L}^{-1}$ de aldicarbe foi preparada em acetonitrila (grau HPLC) e armazenada em freezer. A partir da diluição da solução estoque, obteve-se uma solução padrão de trabalho na concentração de $5 \mathrm{mg} \mathrm{L}^{-1} \mathrm{e}$, posteriormente, esta solução de trabalho foi diluída a fim de se obter as concentrações de 2 $\mathrm{mg} \mathrm{L}^{-1}, 1 \mathrm{mg} \mathrm{L}^{-1}, 0,5 \mathrm{mg} \mathrm{L}^{-1} \mathrm{e} 0,1 \mathrm{mg} \mathrm{L}^{-1}$.

\subsection{Extração de aldicarbe nas amostras de água}

Nos ensaios experimentais foi utilizada ométodo de Extração Líquido-Líquido com Partição à Baixa Temperatura (ELL-PBT) proposta por Goulart e colaboradores (2010), com modificações. Esse método de extração foi otimizado e validado para análise de carbamatos (aldicarbe, carbofurano e carbaril) em água. $\mathrm{O}$ método consistiu em acrescentar em 2,00 mL de amostra de água, $1,5 \%$ de $\mathrm{NaCl}$ e $4,00 \mathrm{~mL}$ deacetonitrila. Em seguida, o sistema foi agitado por 30 segundos em agitador de tubo vórtex. Para a partição à baixa temperatura as matrizes foram colocadas em freezer a $-20^{\circ} \mathrm{C}$ por um período de 3 horas. Posteriormente $1 \mathrm{~mL}$ do extrato orgânico foi retirado e levado para análise cromatográfica.

\subsection{Condições cromatográficas}

Para a quantificação doaldicarbe nas matrizes, foi utilizado um cromatógrafo líquido LC-20AT, Shimadzu equipado com um detector UV/VIS Shimadzu SPD 20A, forno da coluna, Shimadzu CTO 10ASVP, injetor automático Shimadzu SIL 10AF; sistema de integração LabSolutions da Shimadzu. As condições cromatográficas utilizadas foram: Coluna Kinetex $5 \mu \mathrm{m}$ EVO C 18 - 150 X 4,6 mm; Fase móvel (modo isocrático), água deionizada: acetonitrila 50:50 v:v; Fluxo da fase móvel 0,8 mL. $\mathrm{min}^{-1}$; Tempo de corrida 5 minutos; Detector ultravioleta a $195 \mathrm{~nm}$; Pressão da bomba $67 \mathrm{kgf}$ e Temperatura do forno da coluna $35^{\circ} \mathrm{C}$.

\section{RESULTADOS E DISCUSSÃO:}

\section{1. Área de estudo}

Os locais de coleta estão situados dentro da bacia hidrográfica do Rio Paranaíba. A ocupação da bacia do Rio Paranaíba iniciou-se com a mineração de ouro. Com o declínio da mineração a partir dos anos 70 , a região passou a depender da agricultura e da pecuária de subsistência. A partir da década de 50 , é iniciada a produção de café na região de Araguari e a instalação de empreendimentos de maior porte econômico. No final da década de 90, ocorre o ingresso da agricultura irrigada e a grande expansão do cultivo de cana-de-açúcar, confirmando a vocação agroindustrial da bacia. Esta bacia é a segunda maior unidade da Região Hidrográfica do Paraná, ocupando $25,4 \%$ de sua 
área. Posicionada na região central do Brasil, ocupa cerca de $2,6 \%$ do território nacional e inclui os estados de Goiás (63,3\%), Mato Grosso do Sul $(3,4 \%)$ e Minas Gerais (31,7\%), além do Distrito Federal $(1,6 \%)(\mathrm{CBH}, 2014)$.

O uso agrícola na bacia está relacionado, principalmente, aos cultivos de soja, café, milho e feijão e, especialmente, a cana-de-açúcar (cultura esta utilizada para a produção de álcool e açúcar que se expandiu fortemente na bacia). Segundo a Produção Agrícola Municipal alguns municípios da região central da bacia produzem tanto cana-de-açúcar quanto soja em grande escala, ou seja, com mais de 10.000 ha colhidos. A irrigação é o principal uso de água na bacia, vale ressaltar que a bacia apresenta uma grande variedade de culturas irrigadas, tais como canade-açúcar, café e milho, com diferentes métodos que vão desde o gotejamento até pivô central (CBH, 2014).

A Figura 2 apresenta informações sobre a hidrografia e os limites territoriais da bacia hidrográfica do Rio Paranaíba.

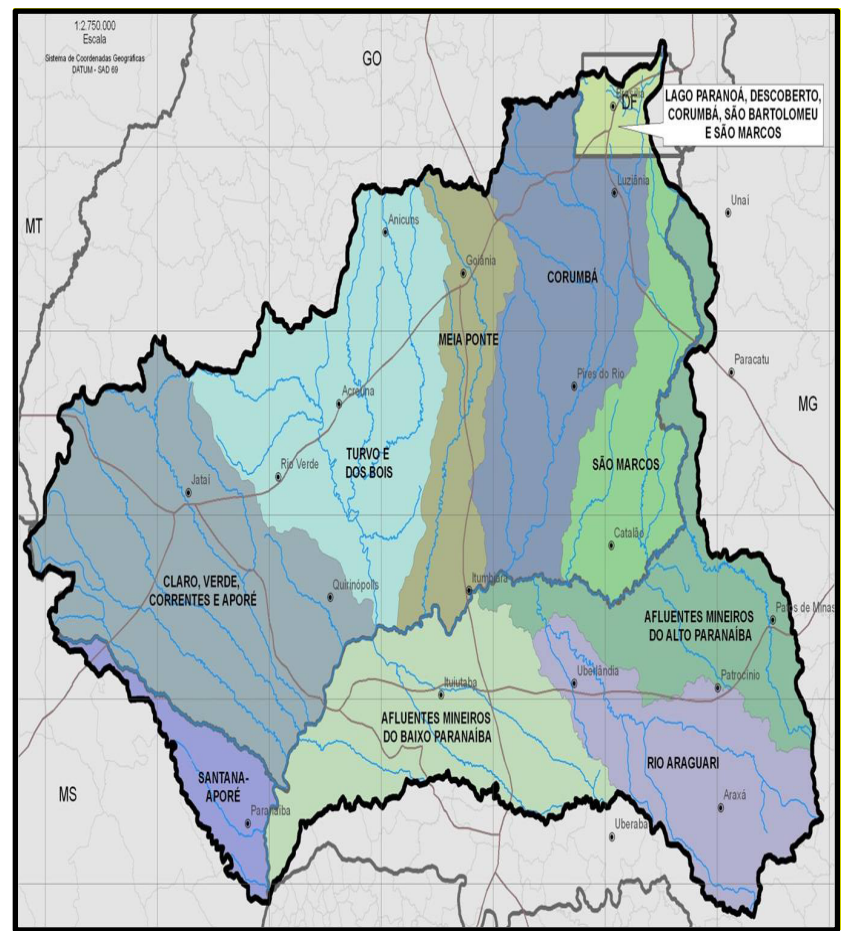

Figura 2:Bacia Hidrográfica do Rio Paranaíba. Fonte: Agência Nacional de águas (2015).

\subsection{Curva analítica}

$\mathrm{Na}$ Figura 3 é apresentada a curva analítica obtida a partir de soluções do padrão de aldicarbe em diferentes concentrações.

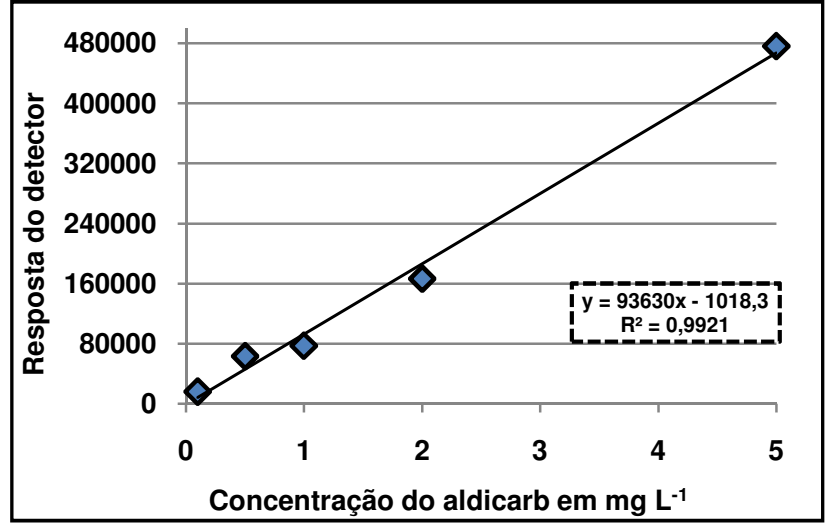

Figura 3: Curva analítica do padrão aldicarbe em diferentes concentrações.

Como visto na Figura 3, a curva analítica apresentou coeficiente de determinação $\left(R^{2}\right)$ igual a 0,99210 que demonstra a linearidade das respostas do detector na faixa de concentração estudada. Segundo (ANVISA, 2003) quanto mais próximo de 1 é o coeficiente de determinação melhor será o ajustamento dos dados e mais explicativo será o modelo.

\subsection{Análise cromatográfica}

Para verificação do tempo de retenção do aldicarbe foi injetado uma solução do padrão de aldicarbe, em acetonitrila, a $5 \mathrm{mgL}^{-1}$. Como visto na Figura 4, as condições cromatográficas foram eficientes para análise do princípio ativo apontando tempo de retenção de 2,475 minutos.

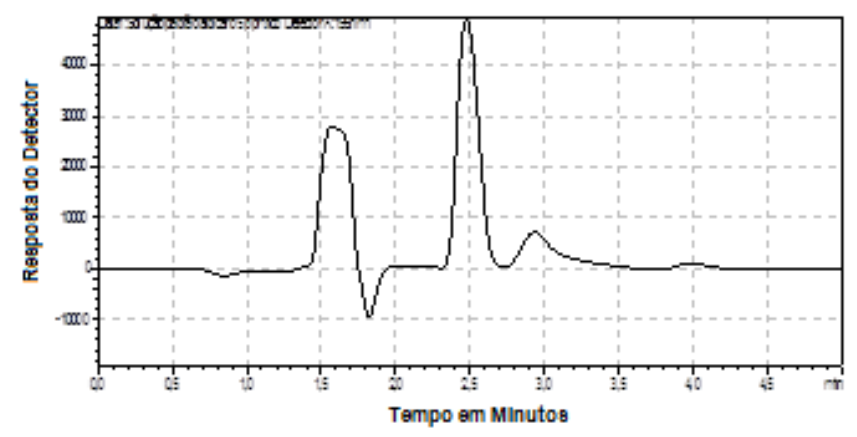

Figura 4:Cromatograma solução padrão de aldicarbe a $5 \mathrm{mg} \mathrm{L}^{-1}$

\subsection{Análise de aldicarbe em águas superficiais do Rio Paranaíba usando a ELL-PBT}

Em cada ponto delimitado, foram coletadas três amostras de águas superficiais, e as análises de cada amostra realizadas em triplicata utilizando a ELL-PBT. Os 
cromatogramas obtidos com os extratos de cada ponto analisado podem ser vistos na Figura 5.

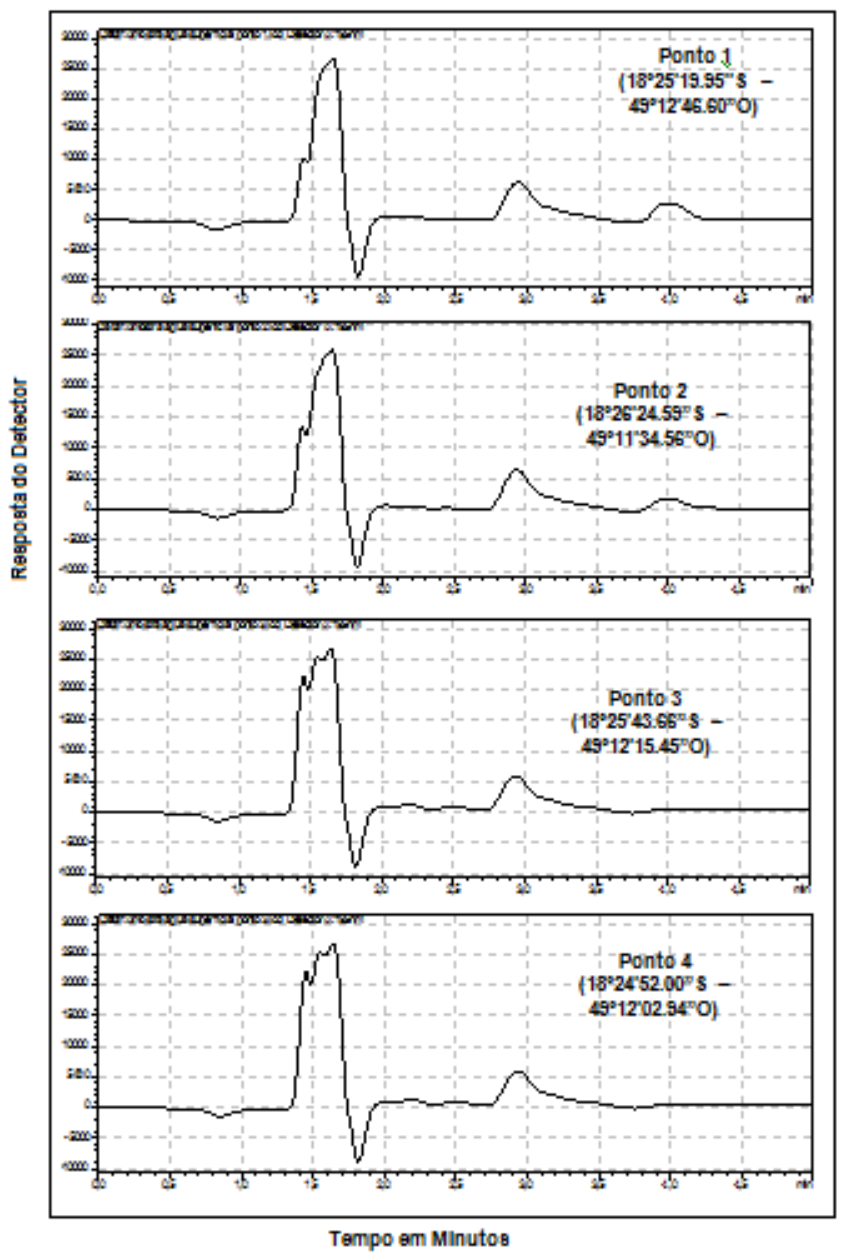

Figura 5:Cromatogramasobtidos a partir da ELL$P B T$ nas amostras de águas superficiaisprovenientes do Rio Paranaíba.

Como pôde ser observado nos 4 cromatogramas dispostos na Figura 5, não houve a presença de picos no tempo de retenção do aldicarbe 2, 475 minutos. Esta observação indica que, nas condições de análises estabelecidas, não foi verificada a presença de resíduos de aldicarbe nos quatro pontos analisados. De acordo com Goulart e colaboradores (2010) o limite de detecção para aldicarbe utilizando o método de extração ELL-PBT e análise por HPLC-UV é $10,0 \mu \mathrm{g} \mathrm{L}^{-1}$, isso significa que em concentrações inferiores a esse valor, não há possibilidade de detecção de aldicarbe nas amostras.

O método de extração do aldicarbe nas amostras de água superficial foi a ELL-PBT desenvolvida por Goulart e colaboradores (2010). A purificação de extratos por meio da partição a baixa temperatura vem sendo utilizada para determinação de uma vasta gama de agrotóxicos em diferentes tipos de amostras como, por exemplo, a determinação de clorpirifos, $\lambda$ cihalotrina, cipermetrina e deltametrina em matrizes de mel (PINHO et al., 2010); Carbamatos, inclusive aldicarbe, em bebidas como suco de uva e leite achocolatado por Goulart et al. (2012); Bifenilaspolicloradas em lodo de esgoto (MAIA et al., 2017); Determinação simultânea de 9 agrotóxicos em matrizes de alface (COSTA et al., 2015). Além de muito utilizada, a técnica apresenta praticidade e pouco consumo de solvente extrator e amostras, sendo ambientalmente menos poluente se comparada às demais técnicas de extração de agrotóxicos.

No Brasil não há parâmetro para a presença de aldicarbe em águas superficiais. Para o carbamatocarbaril, a concentração máxima em água, estabelecida pelo CONAMA é igual a $0,02 \mu \mathrm{g} \mathrm{L}^{-1}$ e $70,0 \mu \mathrm{g} \mathrm{L}^{-1}$ para as Classes I e III, respectivamente.

E importante evidenciar que em todos os cromatogramas das amostras de água superficiais analisadas, foram verificados a presença de outros picos em tempos de retenção diferentes do agrotóxico aldicarbe. Os picos encontrados podem ser indícios de que as amostras estudadas podem conter a presença de outros princípios ativos.

Atualmente, o aldicarbe, apesar da sua extrema toxicidade, continua como ingrediente ativo autorizado em culturas específicas, entretanto, a ANVISA publicou uma nota técnica intitulada "Nota técnica da reavaliação do ingrediente ativo aldicarbe" para reavaliação da utilização do aldicarbe uma vez que esse ingredientetem uso irregular e indiscriminado no país como raticida, agente abortivo e ainda em tentativas de homicídio e de suicídio, acarretando um grave problema de saúde pública, devido ao fácil acesso nos centros urbanos. Ainda nesse documento, outro carbamato, o carbofurano, é citado em usos indiscriminados e indevidos.

Esta pesquisa demonstra a relevância e a necessidade de novos estudos, que tenham como objetivo, verificar a contaminação das águas superficiais do Rio Paranaíba por agrotóxicos que são utilizados na agricultura da região.

\section{CONCLUSÕES:}

Nas condições de análise experimentais deste trabalho, pode-se concluir que não foram encontrados níveis de aldicarbe nas amostras de 
água coletadas em quatro pontos de amostragem do Rio Paranaíba. Pesquisas a respeito do Rio Paranaíba são escassas e indicam necessidade de novos estudos analíticos sobre a presença de poluentes nesse manancial. Esse trabalho é uma possibilidade para delinear novas categorias de análise em trabalhos futuros e indicará pontos específicos para análises mais aprofundadas no Rio Paranaíba.

\section{AGRADECIMENTOS:}

Ao Instituto Federal de Goiás - Câmpus Itumbiara, ao Programa de Educacão Tutorial ("PET Quimica: Educacão, Ambiente e Sociedade"), ao NUPEQUI e ao MEC/FNDE pelo apoio financeiro.

\section{REFERÊNCIAS:}

1. ANA. Agencia Nacional de Águas. http://www2.snirh.gov.br/home/webmap/vi ewer. $\quad \mathrm{html}$ ?webmap $=\quad 12001$ b0c557648399f5f6963e81176b8, acesso em junho 2016.

2. BRASIL. ANVISA, Agência nacional de vigilância sanitária.

http://portal.anvisa.gov.br/wps/ wcm/connect/5c720f80474591b499c8dd3 fbc4c6735/aldicarbe.pdf?MOD=AJPERES , acesso em maio 2016.

3. BRASIL. ANVISA, Agência nacional de vigilância sanitária. Nota técnica da reavaliação do ingrediente ativo aldicarbe. http://portal.anvisa.gov.br/documents/111 215/117797/aldicarbe.pdf/1e2e3d0b-cfe54d5c-ad4d-f3bc58dca316?version=1.0, acesso em abril de 2017.

4. BRASIL. ANVISA. RE $\mathrm{n}$ - 899 , de 29/05/2003: Guia para validação de métodos analíticos e bioanalíticos.

5. CBH Paranaíba - Comitê da bacia hidrográfica do Rio Paranaíba. http://cbhparanaiba.org.br/a-

bacia/regioes-hidrograficas, acesso em junho de 2016.

6. Castro, N. R. A; Rigitano, R. L. O.; Lima, J. M.; Bastos, C. J. Pesquisa agropecuária brasileira, v.40, n.8, p.803810.

7. CONAMA - Ministério do Meio Ambiente, Conselho Nacional do Meio AmbienteResolução No. 357 de 17 de março de 2005 Disponível em: <http://www.mma.gov.br/port/conama/res/ res05/res35705.pdf> Acesso em: 25/04/2017.

8. Costa, A. I. G.; Queiroz, M. E. L. R.; Neves, A. A.; Souza, F. A.; Zambolim, L. FoodChemistry (2015), doi: 10.1016/j.foodchem.2015.02.070.

9. Cohen, S. Z.; Wauchope, R. D.; Klein, A. W.; Eadsforth, C. V.; Graney, R. International Union of Pure and Applied Chemistry. 1995 , v. 67 , n. 12 , p. $2109-$ 2148.

10. Goulart, S. M.; Alves, R. D.; Neves, A. A.; Queiroz, J. H.; Assis, T. C.; Queiroz, M. E. L. de. AnalyticaChimica Acta, 2010, v. 671, p. 41-47.

11. Goulart, S. M.; Alves, R. D.; De Paula, W.X.; Queiroz, J.H.; Neves, A.A.; Queiroz, M.E.L.R.Journal of the Brazilian Chemical Society, 2012, v. 23, n. 6, p. 1154-1165.

12. IBAMA/MMA. Instituto Brasileiro do Meio Ambiente http://www.ibama.gov.br/areastematicas-qa/relatorios-de-comercializaca o-de-agrotoxicos/pagina-3, acesso em maio 2016.

13. IBGE, Cidades. Instituto Brasileiro de Geografia e Estatística. http://cidades. ibge.gov.br/xtras/perfil.

php?codmun $=521150$, acesso em maio 2016.

14. Jackson, R.E; Mutch, J.P; Priddle, M.W. Journal of Contaminant Hydrology. 1990, v. 6, p. 21-35, 1990.

15. Londres, F. Agrotóxicos no Brasil: um guia para ação em defesa da vida.2011, 190 p, ISBN 978-85-87116-15-4.

16. Meffe, R., de Bustamante, I. Science of The Total Environment (2014),doi: http://dx.doi.org/10.1016/j.scitotenv.2014. 02.053 . 
17. Maia, M.R.; Arcanjo, A.L.P.; Pinho, G.P.; Silvério, F.O. Journal of the Brazilian Chemical Society, 2017, v. 28, n. 1, p. 179-186.

18. Patrício, F. C.; Rigitano, R. L. O.; Gouvêa, A. V.; Franco, A. A. Ciência eagrotecnologia. 2002, v.26, n.2, p.385391.

19. Pinho, G.P; Neves, A.A; Queiroz, M.E.L.R; Sivério, F.O. FoodControl (2010), doi:http://dx.doi.org/10.1016/j. foodcont.2010.03.006

20. Rodrigues, M. S. M.; Arruda, C. A. C.; Netto, D. P.; Tajiri, A. N. Semina: Ciências Agrárias, Londrina. 2009, v. 30, n. 4, p. 907-914.

21. Rodrigues, V. C.; Goulart, S. M.; Santos, J. P. V.; Ribeiro Filho, H. A.;Castro, L. M.; Bernadeli, A. A.; Gomes, T. C. F. Sinergia. 2016, v. 17 , n. 1, p. 56-62.

22. Richardson, S.D., Ternes, T.A., 2014. Analytical Chemistry (2014), doi:http://dx.doi.org/10.1021/ac500508t.

23. Tomlin, C. D. S. The pesticide manual. 11th ed. Farnham, Surrey, UK: British Crop Protection Council, 2000. USEPA United States Environmental Protection Agency. Pesticides Fact Sheet. 24p.

24. University of Hertfordshire, http://sitem.herts.ac.uk/aeru/ppdb/en/Rep orts/19.htm, acessoemfevereirode 2017.

25. Yadav, I.C.; Devi, N. L. Pesticides Classification and Its Impact on Human and Environment. In book, Environmental Science and engineering, Environmental Science \& Engineering. Edition: Vol. 6: Toxicology, 2017, cap. 7. 